\title{
Centroblastic Lymphoma Post-Transplant Lymphoproliferative Disorder
}

National Cancer Institute

\section{Source}

National Cancer Institute. Centroblastic Lymphoma Post-Transplant Lymphoproliferative Disorder. NCl Thesaurus. Code C7248.

A centroblastic lymphoma that arises in a patient with a history of org an transplantation. 